\title{
Predictors of Digit Survival following Replantation: Quantitative Review and Meta-Analysis
}

\author{
Ashkaun Shaterian ${ }^{1}$ Ramin Rajaii ${ }^{1}$ Melissa Kanack ${ }^{1}$ Gregory R. D. Evans ${ }^{1} \quad$ Amber Leis ${ }^{1}$ \\ ${ }^{1}$ Department of Plastic Surgery, University of California, Irvine, \\ Orange, California, United States

\begin{abstract}
Address for correspondence Ashkaun Shaterian, MD, Department of Plastic Surgery, University of California, Irvine, 200 South Manchester Avenue, Suite 650, Orange, CA 92868, United States (e-mail: ashateri@uci.edu).
\end{abstract}

J Hand Microsurg 2018;10:66-73

\begin{abstract}
Introduction Microsurgical replantation following digital amputation has variable success rates. Sociodemographic factors and surgery-related variables have been shown to influence survival rates; however, few studies have evaluated these data systematically across a combined dataset. Therefore, the objective of this study was to analyze the current literature to identify the predictors of replant survival.

Materials and Methods A literature review was performed using the PubMed/Medline database focused on complete digit amputation/replantation studies. Studies were evaluated for patient and surgery-related variables and their respective effects on survival. Statistical analysis was conducted to identify predictors of survival and derive pooled estimates from the combined dataset.

Results Thirty-two studies representing more than 6,000 digit amputation/replantation cases met inclusion/exclusion criteria. Statistical analysis revealed the number of venous anastomosis ( 0 vs. 1 vs. 2), the number of arterial anastomosis ( 0 vs. 1 vs. 2 ), and the mechanism of injury (sharp cut versus blunt cut versus avulsion versus crush) to influence replant survival $(p<0.05)$. The authors failed to find a significant association between survival and the following variables: age, sex, zone of injury, digit number,

Keywords tobacco use, ischemia time, method of preservation, and use of vein graft.

- amputation

Conclusion Patient- and surgery-related variables affect digit survival following

- digit survival replantation. The etiology of injury can help risk-stratify patients and assist in an

- microsurgical replantation informed decision making process, whereas surgery-related factors can guide surgeon practice to improve clinical outcomes following replantation.
\end{abstract}

\section{Introduction}

Digital amputation is a devastating injury and one that affects approximately 45,000 patients in the United States every year. ${ }^{1}$ Studies have shown that amputations lead to a decreased quality of life due to the physical, psychological, and financial hardships. ${ }^{2,3}$ Microsurgical replantation, however, affords the ability to restore hand function and is attempted under defined indications. Though advances in medicine, improved technology, and identification of prognostics factors have improved results, survival rates continue to vary ranging between 48 and $97 \%$. ${ }^{4,5}$
Predicting success in replant surgery remains a challenging obstacle. To date, numerous authors have studied replant medicine and identified a host of sociodemographic, surgery-related, and injury-related factors influencing digit replant survival. These have included the following: (1) age, (2) sex, (3) zone of injury, (4) digit number, (5) tobacco use, (6) ischemia time, (7) method of preservation, (8) use of vein graft, (9) number of venous/arterial anastomoses, and (10) mechanism of injury. ${ }^{4,6-9}$ With the increased quantity of published data and often conflicting results, interpreting the predictors of replant survival has become difficult. Further, few studies to date have analyzed this vast dataset systematically to draw generalized conclusions. received

October 1, 2017

accepted after revision

December 2, 2017

published online

March 20, 2018
C2018 Society of Indian Hand \& Microsurgeons 
To date, the predictors of replant survival have yet to be clearly elucidated. Previous meta-analysis studies are limited, and most focus either on distal tip amputations or on patient related variables (vs. surgery-related variables) and often include incomplete amputations. ${ }^{6,7,10}$ Therefore, the aim of the this study was to review the current literature and conduct a quantitative statistical analysis to determine which patient- and surgery-related factors predict survival after complete digit amputation. The authors hope that this analysis will provide data to help surgeons risk-stratify replant candidates, manage patient expectations, and improve guidelines for surgical decision making.

\section{Materials and Methods}

\section{Search Methodology and Results}

The authors performed a literature search using PubMed/ Medline databases. The following keywords were used in this search: "finger," "digit," "thumb," "hand," "replant survival," "replantation," "amputation," and "survival." The authors used MeSH terms and keywords and the Boolean operators "AND" and "OR" to create a combined set for the search. Databases were evaluated for all years of publications until 2016 and were last accessed on January 2017. Contact with study authors was attempted, but it did not yield additional data. As shown in - Fig. 1, 1,086 studies were identified from
PubMed/Medline database search. Removal of duplicates yielded 644 studies eligible for subsequent screening. Next, 531 studies were excluded based on the described inclusion/ exclusion criteria and another 81 studies were excluded due to incomplete data or consolidated data that could not be statistically analyzed. This yielded 32 studies that were ultimately included in this final analysis.

\section{Inclusion/Exclusion Criteria}

Inclusion/exclusion criteria were set to identify quality studies of a specific replant population. Inclusion criteria included the following: studies representing prospective or retrospective analyses, studies detailing treatment protocols with survival rates, and studies presenting individual patient data (to be pooled for analysis). The authors then focused their search to include human subjects (versus animal models) representing all age groups that had complete digital amputations (vs. partial amputations or upper extremity amputations). Exclusion criteria included the following: studies combining partial and complete replant data, studies evaluating revascularization data alone, studies with insufficient sample size (i.e., case studies/series $/ n<5$ ), and studies representing reviews/meta-analyses. If studies additionally included partial amputation/replantation data or amputations proximal to the digit, the data were stratified to include only cases that met the inclusion/exclusion criteria.
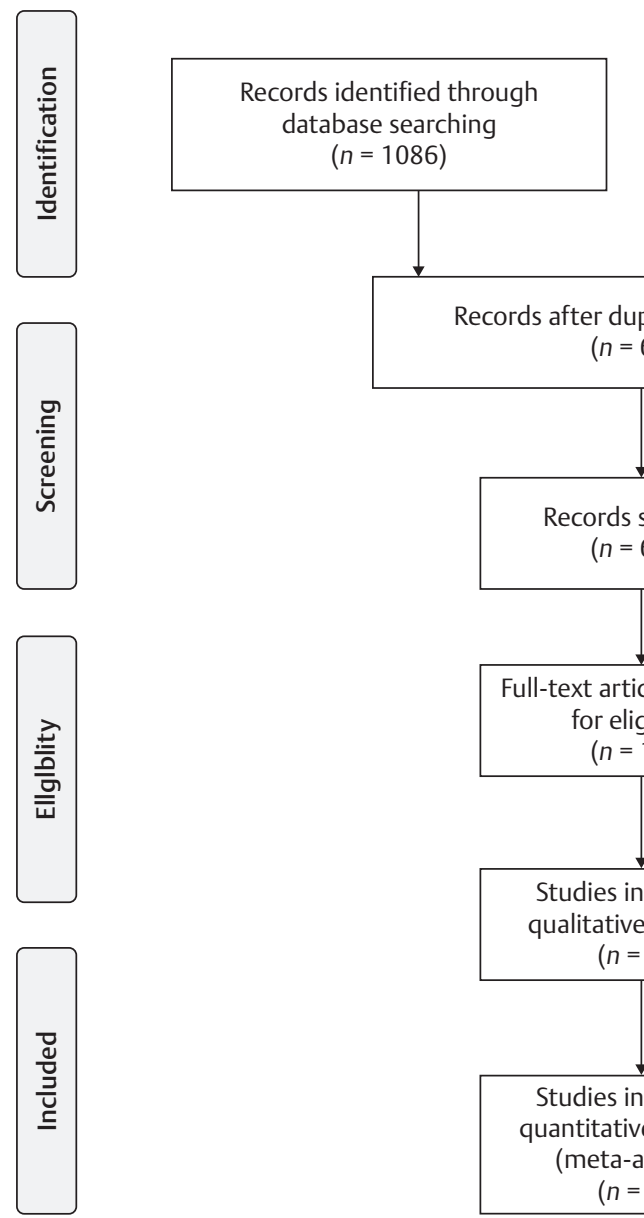
Additional records identified
through other sources $(n=0)$

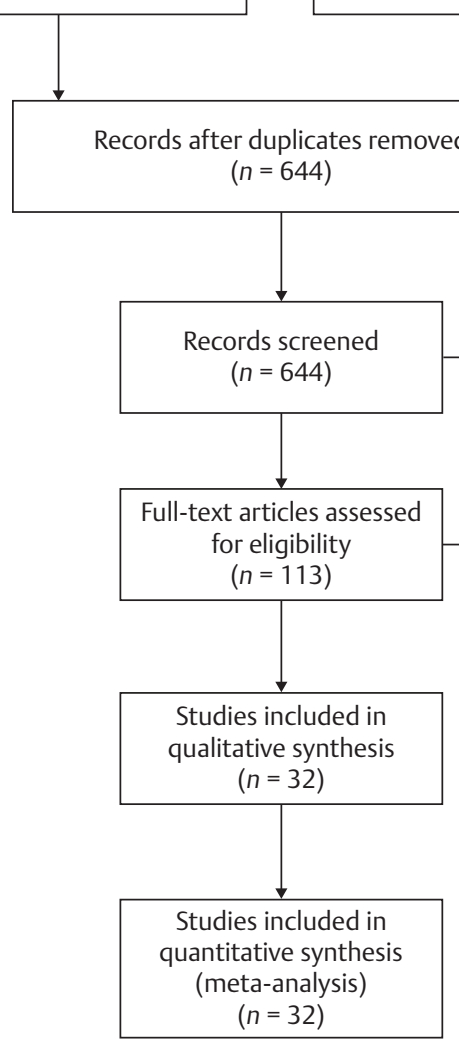

Fig. 1 Study selection process. 


\section{Data Extraction and Statistical Analysis}

Studies fulfilling inclusion/exclusion criteria were evaluated for patient- and surgery-related factors relating to digit survival. Patient-related variables included age, sex, mechanism of injury, zone of injury, specific digit injured, whether single or multiple digits were amputated, and tobacco use. Surgery-related variables included ischemia time, number of arterial anastomoses, number of venous anastomoses, use of vein graft, and method of preservation. Data collection was verified independently by two authors for accuracy. Data were pooled across the different studies and incorporated into statistical analysis. Summary statistics using Student's $t$-test, analysis of variance (ANOVA), and chi-square tests were used where appropriate to evaluate outcomes between treatment groups. Statistical significance was set with $p<0.05$, with all tests two sided.

This study was conducted using the Preferred Reporting Items for Systematic Reviews and Meta-Analyses (PRISMA) guidelines. ${ }^{11}$

\section{Results}

The current analysis included 32 studies representing more than 6,000 digital replants. Study characteristics are summarized in - Table 1. Digit replant survival rate ranged from 48 to $97 \%$ across all studies. Studies were most commonly published between years 2000 and 2016 but ranged from 1985 to 2016. Studies were most commonly published in the United States or an Asian country and included data from the following geographical regions: Brazil, China, Greece, India, Italy, Japan, Korea, Taiwan, United Kingdom, and United States (California, Connecticut, Kentucky, Massachusetts, Missouri, Ohio, North Carolina). When the authors stratified for practice type, they found that 26 studies represented the university hospital setting, five studies represented general hospital practice setting, and one study evaluated the NIS (National [Nationwide] Inpatient Sample) national database comprising both general and university setting practices.

The impact of patient- and surgery-related factors on replant survival after statistical analysis is shown in - Tables 2 and - 3. Here, the authors found (1) the number of arterial anastomoses, (2) number of venous anastomoses, and (3) mechanism of injury to predict digit survival following replantation $(p<0.05)$. When the authors explored the role of arterial anastomoses in replantation, they found that 14 studies $^{12-25}$ evaluated the relationship between arterial anastomoses and replant survival. After analyzing the pooled dataset, the authors found a significant difference in survival rates for digits replanted with zero versus one versus two arterial anastomoses $(p<0.05)$. They found digit replant survival rates of $50.3 \%$ with zero arterial anastomosis, $84.2 \%$ with one arterial anastomosis, and $90.0 \%$ with two arterial anastomoses (-Fig. 2). Survival in the "zero anastomosis" group most commonly represented distal fingertip and pediatric amputations. Few studies documented the need for intraoperative arterial revision or their technique for arterial anastomosis. Though few studies have shown digit survival without arterial anastomoses, improved survival rates can be achieved with increased number of anastomoses.
To evaluate the need for adequate venous drainage in replanted digits, the authors evaluated the relationship between venous anastomoses and replant survival. Here, the authors analyzed 14 studies ${ }^{12,14-22,24-27}$ that explored the relationship between venous anastomoses and replant survival. After conducting statistical analysis, they found a significant difference in survival for digits replanted with zero versus one versus two anastomoses $(p<0.05)$. The authors found $61.1 \%$ survival rates for digits replanted with zero venous anastomosis, 73\% for those with one venous anastomosis, and $92.3 \%$ with two venous anastomoses (- Fig. 3). Several studies evaluated survival following three venous anastomoses replants; however, the sample size was too limited to generalize conclusions. Similarly, too few studies stratified for type of venous anastomosis (suture vs. coupler). Ultimately, though nonanastomoses techniques (i.e., leeches, heparinization, etc.) and dermal/subdermal plexus can provide a level of venous drainage, survival rates are improved with increased number of venous anastomoses.

Next, the authors explored the relationship between the etiology of amputation (sharp cut, blunt cut, avulsion, crush mechanisms) and survival rates following replantation. They pooled data from 20 studies, ${ }^{4,13,15-17,19-22,25,27-36}$ and after conducting this statistical analysis, they found the mechanism of injury to predict replant survival $(p<0.05)$. They found a significant difference in survival rates across the mechanisms of injury with sharp lacerating injuries having the highest rates of survival ( $87.2 \%)$, followed by blunt lacerating injuries (83.0\%), avulsion injuries (71.2\%), and crush injuries (69.4\%) (-Fig. 4). Too few studies stratified for severity of injury or other concomitant life-threatening injuries that may have influenced replant survival. The mechanism of injury can relate with severity of injury during amputation and influences survival rates following replantation.

Statistical analysis revealed that the following variables failed to influence replant survival: age, sex, zone of injury, digit number, tobacco use, ischemia time, method of preservation, and use of vein graft. The authors found that 19 studies evaluated the role of sex and survival, $, 412,13,15-17,20-22,24,25,27-30,32,34,35,3713$ studies evaluated the zone of injury, 13,15-18,21,23,26,27,33,34,36,38 15 studies evaluated digit number, $4,13,15,17,20-22,24,29,32,33,35,39-41$ studies evaluated tobacco use, ${ }^{4,13,15,22,34} 2$ studies evaluated ischemia time, ${ }^{13,32} 2$ studies evaluated method of preservation, ${ }^{15,34}$ and 6 studies evaluated the use of vein grafting. ${ }^{12,13,15,17,20,24}$ Despite several individual studies finding statistically significant correlations between these variables and replant survival, these variables did not maintain significance when evaluated across the pooled dataset $(p>0.05)$. Several studies presented conflicting data whereas others presented nonsignificant data that ultimately negated significance on statistical testing.

\section{Discussion}

In this study, the authors performed a review of the literature and quantitative systematic analysis evaluating the risk factors for survival following digit replantation. Here, they found the number of venous anastomosis, the number of 
Table 1 Study characteristics

\begin{tabular}{|c|c|c|c|c|}
\hline Study & Year & Location & Setting & Survival rate (\%) \\
\hline Adani et al ${ }^{12}$ & 2013 & Italy & University & 88 \\
\hline Baker and Kleinert ${ }^{17}$ & 1994 & United States (Kentucky) & University & 69 \\
\hline Berlin et $\mathrm{al}^{39}$ & 2014 & United States (Connecticut) & Nat'l database & 73 \\
\hline Breahna et al ${ }^{33}$ & 2016 & United Kingdom & General hospital & 70 \\
\hline Chai et al ${ }^{28}$ & 2008 & China & University & 92 \\
\hline Chen et $\mathrm{al}^{29}$ & 2013 & Taiwan & University & 90 \\
\hline Chen et $\mathrm{al}^{30}$ & 2014 & Taiwan & University & 92 \\
\hline Cheng et $\mathrm{al}^{5}$ & 1985 & China & General hospital & 97 \\
\hline Fufa et al ${ }^{13}$ & 2013 & $\begin{array}{l}\text { United States (Missouri, } \\
\text { Ohio) }\end{array}$ & University & 57 \\
\hline Goldner et al ${ }^{20}$ & 1989 & $\begin{array}{l}\text { United States (North } \\
\text { Carolina) }\end{array}$ & University & 81 \\
\hline Gordon et al $\left.\right|^{35}$ & 1985 & United States (California) & University & 71 \\
\hline Hattori et $\mathrm{a}^{21}$ & 2003 & Japan & University & 86 \\
\hline Heistein and Cook ${ }^{34}$ & 2003 & United States (Ohio) & University & $53^{a}$ \\
\hline Hirase $^{23}$ & 1997 & Japan & University & 92 \\
\hline Huang and Yeong ${ }^{14}$ & 2015 & Taiwan & University & 81 \\
\hline Ito et $\mathrm{al}^{26}$ & 2010 & Japan & University & 87 \\
\hline Kim et $\mathrm{al}^{31}$ & 1996 & Korea & University & 78 \\
\hline Koshima et al ${ }^{24}$ & 2005 & Japan & University & $81^{a}$ \\
\hline Lee et $a^{38}$ & 2000 & Korea & University & 77 \\
\hline Li et $a^{15}$ & 2008 & China & University & 82 \\
\hline Lin et $\mathrm{al}^{37}$ & 2010 & Taiwan & University & 68 \\
\hline Lin et $\mathrm{a}^{25}$ & 2004 & Taiwan & University & 94 \\
\hline Malizos et al ${ }^{27}$ & 1994 & Greece & University & 83 \\
\hline Matsuda et al ${ }^{18}$ & 1993 & Japan & General hospital & $75^{\mathrm{a}}$ \\
\hline Mulders et al ${ }^{4}$ & 2013 & $\begin{array}{l}\text { United States } \\
\text { (Massachusetts) }\end{array}$ & University & $48^{a}$ \\
\hline Shi et al ${ }^{49}$ & 2010 & China & University & 91 \\
\hline Urbaniak et al ${ }^{19}$ & 1985 & $\begin{array}{l}\text { United States (North } \\
\text { Carolina) }\end{array}$ & University & 86 \\
\hline $\begin{array}{l}\text { Venkatramani and } \\
\text { Sabapathy }{ }^{16}\end{array}$ & 2011 & India & General hospital & 88 \\
\hline Woo et $\mathrm{al}^{32}$ & 2015 & Korea & General hospital & $86^{\mathrm{a}}$ \\
\hline Yamano $^{36}$ & 1993 & Japan & University & 80 \\
\hline Yin et $a^{22}$ & 2015 & China & University & 87 \\
\hline Zumiotti and Ferreira ${ }^{41}$ & 1994 & Brazil & University & 70 \\
\hline
\end{tabular}

${ }^{a}$ Represent study survival rates after excluding incomplete amputation/revascularization cases (Koshima et al ${ }^{24}$ and Mulders et al ${ }^{4}$ ) and excluding amputations proximal to MCPJ (Matsuda et $\mathrm{al}^{18}$, Woo et al, ${ }^{32}$ and Lin et $\mathrm{al}^{37}$ ).

arterial anastomosis, and the mechanism of injury to predict replant survival. They failed to find a significant association between survival and the following variables: age, sex, zone of injury, digit number, tobacco use, ischemia time, method of preservation, and use of vein graft. Taking all these data together, this study identifies both significant and nonsignificant variables in replant survival that can be used to improve patient outcomes.

Adequate arterial inflow is necessary to avoid ischemia. In this study, the authors found number of arterial anastomosis to predict survival. This likely represents the need for adequate arterial inflow necessary to meet the metabolic demands of the amputated segment. ${ }^{9}$ Studies suggest that adequate capillary perfusion pressures are necessary for tissue viability and thus the necessity of restoring arterial inflow. Furthermore, the results support traditional opinion that suggest that one arterial anastomosis is necessary for replant survival, but two anastomoses can improve survival rates. ${ }^{42}$ Several authors have reported survival rates without arterial anastomosis, however, these results primarily 
Table 2 Quantitative analysis of patient-related factors on replant survival

\begin{tabular}{|c|c|c|c|c|}
\hline Factor & Studies & Comparison & OR & $p$-Value \\
\hline Age & 14 & Child vs. adult & 0.81 & NS \\
\hline Sex & 19 & Male vs. female & 1.02 & NS \\
\hline \multirow[t]{4}{*}{ Mechanism of injury } & \multirow[t]{4}{*}{20} & Sharp cut & Ref & \multirow[t]{4}{*}{$<0.05$} \\
\hline & & Blunt cut & 0.95 & \\
\hline & & Avulsion & 0.82 & \\
\hline & & Crush & 0.80 & \\
\hline \multirow[t]{5}{*}{ Digit number } & \multirow[t]{5}{*}{15} & Thumb & Ref & \multirow[t]{5}{*}{ NS } \\
\hline & & Index & 0.94 & \\
\hline & & Middle & 1.00 & \\
\hline & & Ring & 1.01 & \\
\hline & & Small & 0.93 & \\
\hline \multirow[t]{5}{*}{ Zone of injury } & \multirow[t]{5}{*}{13} & Tamai zones: & & \multirow[t]{5}{*}{ NS } \\
\hline & & 1 & Ref & \\
\hline & & II & 1.01 & \\
\hline & & III & 0.87 & \\
\hline & & IV & 0.99 & \\
\hline Tobacco use & 5 & Tobacco use vs. no tobacco & 0.80 & NS \\
\hline \multirow[t]{3}{*}{ Ischemia time } & \multirow[t]{3}{*}{2} & $<6 \mathrm{~h}$ & Ref & \multirow[t]{3}{*}{ NS } \\
\hline & & $6-10 \mathrm{~h}$ & 1.49 & \\
\hline & & $>10 \mathrm{~h}$ & 1.34 & \\
\hline Method of preservation & 2 & Cold vs. warm/room temperature & 0.94 & NS \\
\hline
\end{tabular}

Abbreviations: NS, not significant; OR, odds ratio.

Table 3 Quantitative analysis of surgery-related factors on replant survival

\begin{tabular}{|c|c|c|c|c|}
\hline Factor & Studies & Comparison & OR & $p$-Value \\
\hline \multirow[t]{3}{*}{ No. of arterial anastomosis } & \multirow[t]{3}{*}{14} & 0 & Ref & \multirow[t]{3}{*}{$<0.05$} \\
\hline & & 1 & 1.67 & \\
\hline & & 2 & 1.79 & \\
\hline \multirow[t]{3}{*}{ No. of venous anastomosis } & \multirow[t]{3}{*}{14} & 0 & Ref & \multirow[t]{3}{*}{$<0.05$} \\
\hline & & 1 & 1.19 & \\
\hline & & 2 & 1.51 & \\
\hline Vein graft & 6 & Graft vs. no graft & 0.99 & NS \\
\hline
\end{tabular}

Abbreviations: NS, not significant; OR, odds ratio.

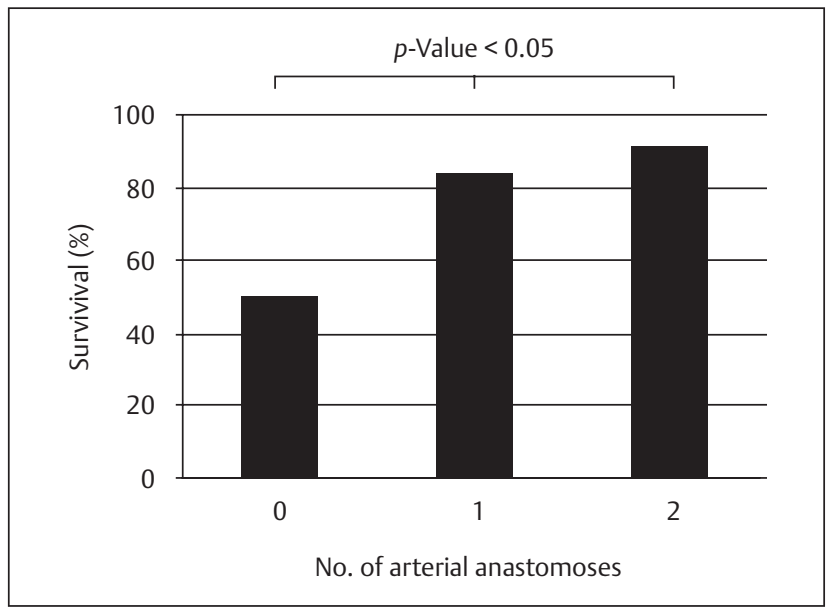

Fig. 2 Effect of arterial anastomoses on survival.

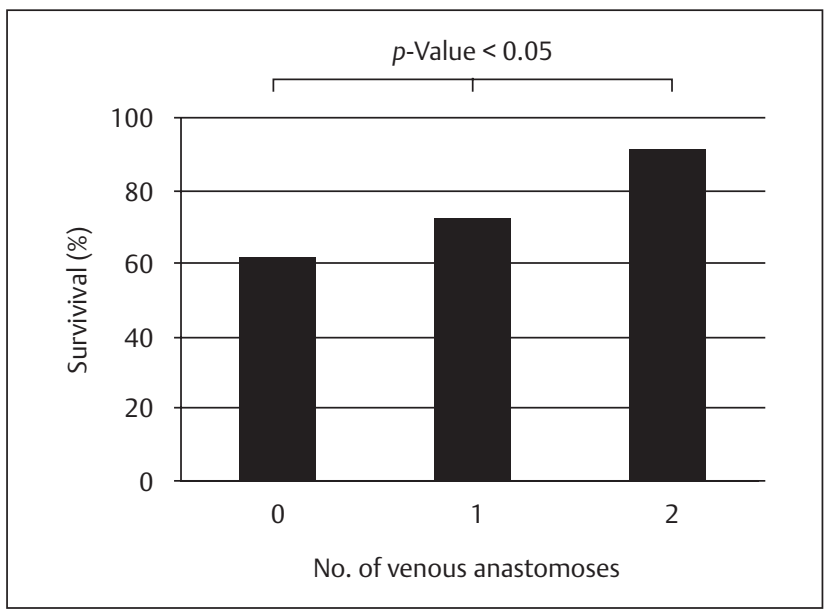

Fig. 3 Effect of venous anastomoses on survival. 


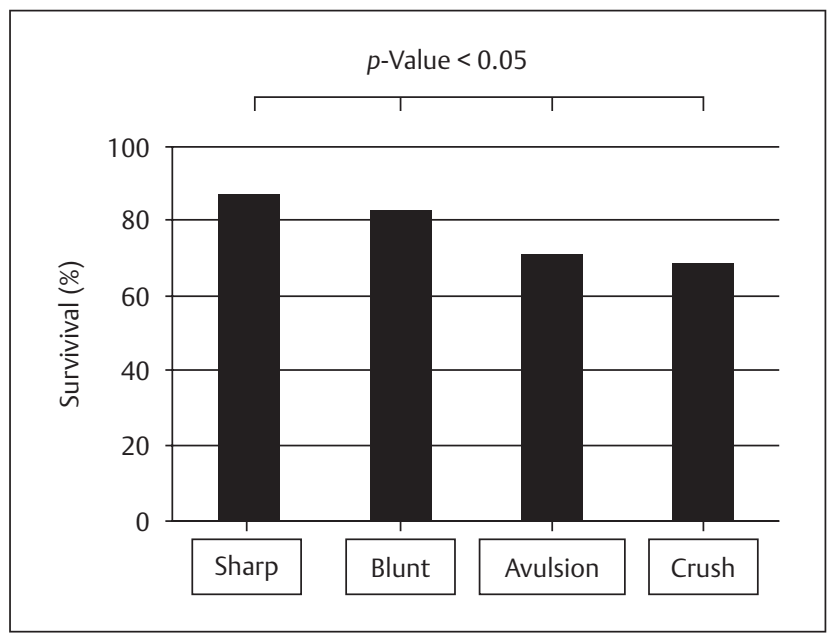

Fig. 4 Effect of mechanism of injury on survival.

represent amputations in the pediatric population or distal fingertip amputations. ${ }^{16,23}$ Ultimately, arterial inflow is necessary for replant survival wherein surgeons can improve survival rates intraoperatively by increasing the number of arterial anastomoses.

Venous congestion results from inadequate venous outflow and is commonly encountered following tissue replantation when venous anastomosis may not be technically possible (i.e., ear, lips). ${ }^{43-45}$ In this study, the authors found the number of venous anastomosis to predict replant survival. This likely represents the need for adequate venous drainage to prevent venous congestion and subsequent edema, increased interstitial space pressures, arterial insufficiency, and the accumulation of metabolites. ${ }^{46,47}$ Though medical leech application, arteriovenous anastomosis, and local heparin administration can improve venous insufficiency, ${ }^{10}$ formal venous anastomoses should be prioritized. These data are further supported by the partial amputation/revascularization data that suggest skin bridges may not provide adequate venous outflow and necessitate formal venous anastomoses. ${ }^{48}$ To this end, survival of a replanted digit can be optimized intraoperatively by increasing the number of venous anastomoses.

The mechanism of injury often gives insight into the severity of tissue damage in surgical/trauma patients. In this study, the authors found the mechanism of injury to predict survival with sharp and blunt lacerating injuries having higher survival rates than crush/avulsion injuries. The mechanism of injury likely affects replant survival through its effects on the vasculature. The rotational stretching, crushing, and tearing components characteristic of avulsion and crush injuries lead to a larger zone of injury and more severe vessel damage., ${ }^{9,17}$ Damaged vessel endothelium and trauma-related contusion of the microvasculature increase the risk for thrombosis and subsequent replant failure. ${ }^{9,17}$ The more frequent use of vein grafts in avulsion and crush injuries to circumvent the zone of injury has been cited by the authors as contributing to higher rates of success with these injuries. ${ }^{8}$ Lacerating injuries, in contrast, have minimal soft tissue damage and a defined zone of vessel injury that does not extend greatly beyond the laceration itself. As such, survival rates for lacerating injuries are improved. Ultimately, the mechanisms of injury correlate with vessel injury and subsequent replant failure and can be a prognostic factor to help educate patients and improve the patient-physician decision-making process.

Several variables were reported to correlate with survival in the literature; however, they did not maintain significance after this systematic analysis. These variables included age, sex, zone of injury, digit number, tobacco use, ischemia time, method of preservation, and the use of vein grafts. Though many of these variables have physiologic reasons to explain a relationship with survival, they failed to reach statistical significance when analyzing the pooled dataset. This likely represents the lack of a significant relationship with survival and conflicting data across studies. It may also, in part, reflect underpowered statistics for a given variable (i.e., zone of injury) or the nonuniform categorization of variables across studies precluding pooled analyses (i.e., ischemia times). Ultimately, additional research is necessary to evaluate further the role of these variables in replant survival.

This study has several limitations. First, it represents a review of retrospective studies and risks of unmeasured and unaccounted bias. A comprehensive review of literature was performed; however, this study risks incomplete retrieval of identified research and reporting biases of published data. This study included studies from various time periods and countries that may influence the standard of practice. Next, this study was unable to address the role of surgical skill or years of experience in replantation, which can affect success rates. Furthermore, there is significant variability in the method of data collection as various descriptors were not standardized (i.e., different descriptors for zone of injury, different ischemia time intervals). This variability decreases the sample size and may underscore otherwise significant associations. Last, though the data evaluated replant survival, the authors did not evaluate or correlate quality of hand function in these replanted patients.

The significant variables identified in this study can be used to help guide surgeon practice and guide patient decision-making. They can be used in preoperative patient counseling and risk stratification, as well as influence intraoperative proficiency. Additional research and data are needed in the field of replant medicine to better characterize the predictors of survival and functional outcomes following replant. The authors hope that, with additional data and advancing technology, rates of digit replant can be improved and standardized across different injury patterns and patient presentations.

\section{Conclusion}

Digital amputation is a debilitating injury and one that has variable rates of survival following replantation. This 
systematic review of the literature and quantitative statistical analysis showed the number of arterial anastomoses, number of venous anastomoses, and mechanisms of injury to predict replant survival following digit amputation. Though additional research is needed, the authors feel these data can be used to help guide surgeon practice and provide prognostic data to assist further in the physician-patient decision-making process.

\section{Conflict of Interest}

None.

\section{References}

1 Mahmoudi E, Swiatek PR, Chung KC, Ayanian JZ. Racial variation in treatment of traumatic finger/thumb amputation: a national comparative study of replantation and revision amputation. Plast Reconstr Surg 2016;137(3):576e-585e

2 Tessler O, Bartow MJ, Tremblay-Champagne MP, et al. Longterm health-related quality of life outcomes in digital replantation versus revision amputation. J Reconstr Microsurg 2017;33(6):446-451

3 Bhuvaneswar CG, Epstein LA, Stern TA. Reactions to amputation: recognition and treatment. Prim Care Companion J Clin Psychiatry 2007;9(4):303-308

4 Mulders MA, Neuhaus V, Becker SJ, Lee SG, Ring DC. Replantation and revascularization vs. amputation in injured digits. Hand (NY) 2013;8(3):267-273

5 Cheng GL, Pan DD, Yang ZX, Qu ZY. Replantation of digits amputated at or about the distal interphalangeal joint. Ann Plast Surg 1985;15(6):465-473

6 Yu H, Wei L, Liang B, Hou S, Wang J, Yang Y. Nonsurgical factors of digital replantation and survival rate: a metaanalysis. Indian J Orthop 2015;49(3):265-271

7 Ma Z, Guo F, Qi J, Xiang W, Zhang J. Effects of non-surgical factors on digital replantation survival rate: a meta-analysis. J Hand Surg Eur Vol 2016;41(2):157-163

8 Sharma S, Lin S, Panozzo A, Tepper R, Friedman D. Thumb replantation: a retrospective review of 103 cases. Ann Plast Surg 2005;55(4):352-356

9 Zhong-Wei C, Meyer VE, Kleinert HE, Beasley RW. Present indications and contraindications for replantation as reflected by long-term functional results. Orthop Clin North Am 1981;12(4):849-870

10 Sebastin SJ, Chung KC. A systematic review of the outcomes of replantation of distal digital amputation. Plast Reconstr Surg 2011;128(3):723-737

11 Moher D, Liberati A, Tetzlaff J, Altman DG, Group P; PRISMA Group. Preferred reporting items for systematic reviews and meta-analyses: the PRISMA statement. Int J Surg 2010;8(5):336-341

12 Adani R, Pataia E, Tarallo L, Mugnai R. Results of replantation of 33 ring avulsion amputations. J Hand Surg Am 2013;38(5):947-956

13 Fufa D, Calfee R, Wall L, Zeng W, Goldfarb C. Digit replantation: experience of two U.S. academic level-I trauma centers. J Bone Joint Surg Am 2013;95(23):2127-2134

14 Huang HF, Yeong EK. Surgical treatment of distal digit amputation: success in distal digit replantation is not dependent on venous anastomosis. Plast Reconstr Surg 2015;135(1):174-178

15 Li J, Guo Z, Zhu Q et al. Fingertip replantation: determinants of survival. Plast Reconstr Surg 2008;122(3):833-839

16 Venkatramani H, Sabapathy SR. Fingertip replantation: technical considerations and outcome analysis of 24 consecutive fingertip replantations. Indian J Plast Surg 2011;44(2):237-245
17 Baker GL, Kleinert JM. Digit replantation in infants and young children: determinants of survival. Plast Reconstr Surg 1994;94(1):139-145

18 Matsuda M, Chikamatsu E, Shimizu Y. Correlation between number of anastomosed vessels and survival rate in finger replantation. J Reconstr Microsurg 1993;9(1):1-4

19 Urbaniak JR, Roth JH, Nunley JA, Goldner RD, Koman LA. The results of replantation after amputation of a single finger. J Bone Joint Surg Am 1985;67(4):611-619

20 Goldner RD, Stevanovic MV, Nunley JA, Urbaniak JR. Digital replantation at the level of the distal interphalangeal joint and the distal phalanx. J Hand Surg Am 1989;14(2 Pt 1):214-220

21 Hattori Y, Doi K, Ikeda K, Abe Y, Dhawan V. Significance of venous anastomosis in fingertip replantation. Plast Reconstr Surg 2003;111(3):1151-1158

22 Yin F, Mi JY, Rui YJ, et al. [Risk factors of the failure in digit replantation] Zhongguo Gu Shang 2015;28(5):429-432

23 Hirase Y. Salvage of fingertip amputated at nail level: new surgical principles and treatments. Ann Plast Surg 1997;38(2):151-157

24 Koshima I, Yamashita S, Sugiyama N, Ushio S, Tsutsui T, Nanba Y. Successful delayed venous drainage in 16 consecutive distal phalangeal replantations. Plast Reconstr Surg 2005;115(1):149-154

25 Lin TS, Jeng SF, Chiang YC. Fingertip replantation using the subdermal pocket procedure. Plast Reconstr Surg 2004;113(1):247-253

26 Ito H, Sasaki K, Morioka K, Nozaki M. Fingertip amputation salvage on arterial anastomosis alone: an investigation of its limitations. Ann Plast Surg 2010;65(3):302-305

27 Malizos KN, Beris AE, Kabani CT, Korobilias AB, Mavrodontidis AN, Soucacos PN. Distal phalanx microsurgical replantation. Microsurgery 1994;15(7):464-468

28 Chai Y, Kang Q, Yang Q, Zeng B. Replantation of amputated finger composite tissues with microvascular anastomosis. Microsurgery 2008;28(5):314-320

29 Chen YC, Chan FC, Hsu CC, Lin YT, Chen CT, Lin CH. Fingertip replantation without venous anastomosis. Ann Plast Surg 2013;70(3):284-288

30 Chen KK, Hsieh TY, Chang KP. Tamai zone I fingertip replantation: is external bleeding obligatory for survival of artery anastomosis-only replanted digits? Microsurgery 2014; 34(7):535-539

31 Kim WK, Lim JH, Han SK. Fingertip replantations: clinical evaluation of 135 digits. Plast Reconstr Surg 1996;98(3):470-476

32 Woo SH, Cheon HJ, Kim YW, Kang DH, Nam HJ. Delayed and suspended replantation for complete amputation of digits and hands. J Hand Surg Am 2015;40(5):883-889

33 Breahna A, Siddiqui A, Fitzgerald O'Connor E, Iwuagwu FC. Replantation of digits: a review of predictive factors for survival. J Hand Surg Eur Vol 2016;41(7):753-757

34 Heistein JB, Cook PA. Factors affecting composite graft survival in digital tip amputations. Ann Plast Surg 2003;50(3):299-303

35 Gordon L, Leitner DW, Buncke HJ, Alpert BS. Partial nail plate removal after digital replantation as an alternative method of venous drainage. J Hand Surg Am 1985;10(3):360-364

36 Yamano Y. Replantation of fingertips. J Hand Surg [Br] 1993;18(2):157-162

37 Lin CH, Aydyn N, Lin YT, Hsu CT, Lin CH, Yeh JT. Hand and finger replantation after protracted ischemia (more than 24 hours). Ann Plast Surg 2010;64(3):286-290

38 Lee BI, Chung HY, Kim WK, Kim SW, Dhong ES. The effects of the number and ratio of repaired arteries and veins on the survival rate in digital replantation. Ann Plast Surg 2000;44(3):288-294

39 Berlin NL, Tuggle CT, Thomson JG, Au A. Digit replantation in children: a nationwide analysis of outcomes and trends of 455 pediatric patients. Hand (NY) 2014;9(2):244-252 
40 Chia DS, Tay SC. A retrospective review of troubled replantations. Hand Surg 2015;20(1):127-132

41 Zumiotti A, Ferreira MC. Replantation of digits: factors influencing survival and functional results. Microsurgery 1994; 15(1):18-21

42 Green DP, Wolfe SW. Green's Operative Hand Surgery 6th ed. Philadelphia, PA: Saunders/Elsevier; 2011:1585-1603

43 Juri J, Irigaray A, Juri C, Grilli D, Blanco CM, Vazquez GD. Ear replantation. Plast Reconstr Surg 1987;80(3):431-435

44 Nahai F, Hayhurst JW, Salibian AH. Microvascular surgery in avulsive trauma to the external ear. Clin Plast Surg 1978; 5(3):423-426
45 Baj A, Beltramini G, Laganà F, Bonanno V, De Riu G, Giannì A. Amputation trauma of the face: surgical techniques and microsurgical replantations. Acta Otorhinolaryngol Ital 2009;29(2):92-96

46 Morrison WA, McCombe D. Digital replantation. Hand Clin 2007;23(1):1-12

47 Maricevich M, Carlsen B, Mardini S, Moran S. Upper extremity and digital replantation. Hand (NY) 2011;6(4):356-363

48 Saies AD, Urbaniak JR, Nunley JA, Taras JS, Goldner RD, Fitch RD. Results after replantation and revascularization in the upper extremity in children.J Bone Joint Surg Am 1994;76(12):1766-1776

49 Shi D, Qi J, Li D, et al. Fingertip Replantation at or beyond the Nail Base in Children. Microsurgery 2010;30(5):380-385 